\title{
Pharmacovigilance in Qatar: a survey of pharmacists
}

\author{
K. Wilbur ${ }^{7}$
}

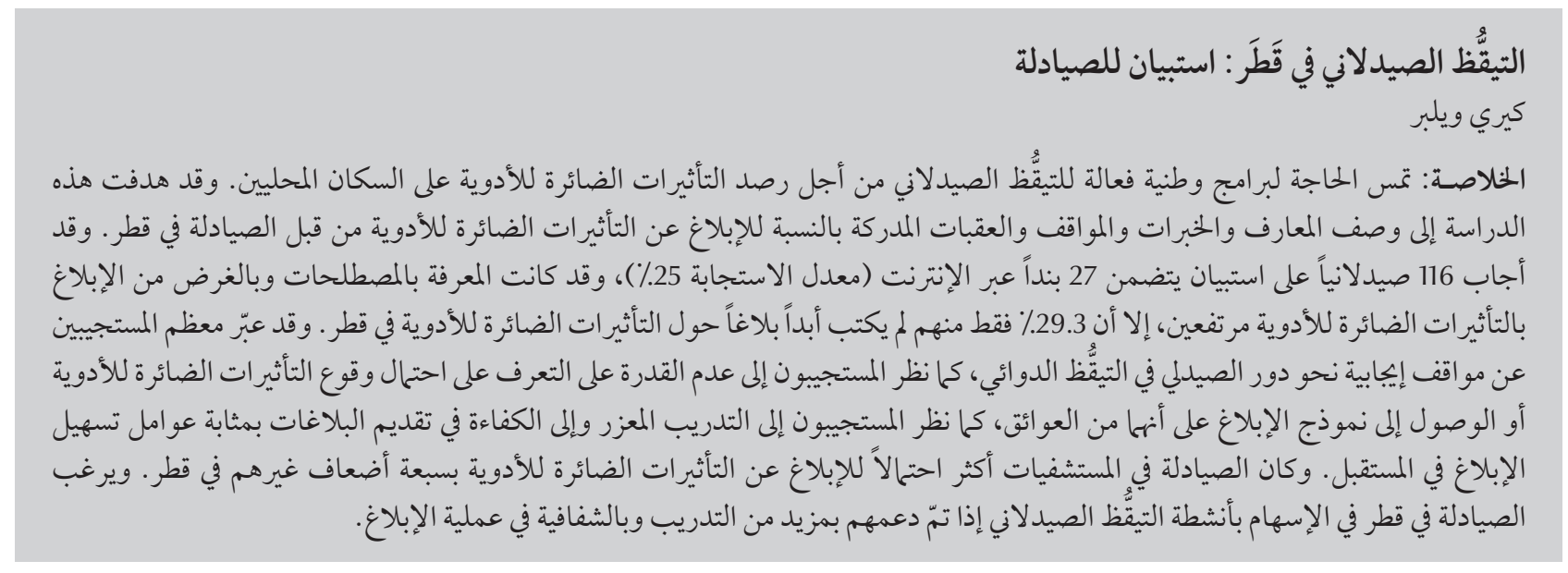

ABSTRACT Active national pharmacovigilance programmes are needed to monitor adverse drug reaction (ADR) data in local populations. The objective of this study was to describe the knowledge, experiences, attitudes and perceived barriers to reporting of suspected ADRs by pharmacists in Qatar. A 27-item web-based survey was answered by 116 pharmacists (25\% response rate). Knowledge of ADR terminology and reporting purpose was high, but only 29.3\% had ever made a suspected ADR report in Qatar. Most respondents expressed positive attitudes towards the pharmacist's role in pharmacovigilance. Inability to recognize a potential ADR or access a reporting form were perceived as barriers. Enhanced training and efficiency in report submissions were identified as facilitators to future participation. Hospital pharmacists were 7 times more likely to have reported a suspected ADR in Qatar. Pharmacists in Qatar are willing to engage in pharmacovigilance activities if supported by increased training and transparency in the reporting process.

\section{Pharmacovigilance au Qatar : enquête auprès des pharmaciens}

RÉSUMÉ Des programmes de pharmacovigilance nationaux actifs sont requis pour surveiller les données relatives aux réactions indésirables aux médicaments dans les populations locales. L'objectif de la présente étude était de décrire les connaissances, les expériences, les attitudes et les obstacles perçus en matière de notification des réactions indésirables par les pharmaciens au Qatar. 116 pharmaciens ont répondu à une enquête en ligne à 27 items (taux de réponse de $25 \%$ ). Leur niveau de connaissances en ce qui concerne la terminologie pour les réactions indésirables et les objectifs de notification était élevé, mais seuls 29,3\% d'entre eux avaient déjà notifié une suspicion de réaction indésirable au Qatar. La majorité des répondants ont présenté des attitudes positives au sujet du rôle du pharmacien en matière de pharmacovigilance. L'incapacité à reconnaitre une réaction indésirable potentielle ou à accéder à un formulaire de notification ont été perçus comme des obstacles. Une formation et une efficacité accrues dans la transmission des notifications ont été identifiées comme des facteurs favorisant une future participation. Les pharmaciens hospitaliers étaient sept fois plus susceptibles d'avoir notifié une suspicion de réaction indésirable que les autres pharmaciens dans le pays. Les pharmaciens au Qatar sont disposés à s'impliquer dans des activités de pharmacovigilance s'ils bénéficient d'une formation et d'une transparence accrues pour le processus de notification. 


\section{Introduction}

Suspected adverse drug reaction (ADR) reporting is the cornerstone of pharmacovigilance activity; however, its infrastructure varies throughout the world. Surveillance programmes within individual health care facilities may supplement a central national registry, which may in turn augment an international database. Most reporting systems are voluntary and while spontaneous reporting offers advantages of low expense and less complexity, barriers such as time, ambiguity in ADR identification and lack of feedback contribute to under-reporting in several countries [1-6].

Qatar is an affluent Arab emirate with a population of 1.9 million (predominantly expatriates). The Qatar Supreme Council of Health (SCH) has a pharmacy and drug control department subdivision assuming various medication regulation roles, but there is no coordinated national pharmacovigilance programme. A recent inventory of pharmacovigilance activity in Qatar inpatient settings found that suspected ADR reporting policies and procedures are in place within all public hospitals, but in only 1 of the 5 private hospitals [7].

The success of any surveillance system relies on the active participation of its reporters and is the responsibility of everyone involved in the medication use process. Pharmacists working in Qatar are a multinational group, emerging from heterogeneous curricula and training programmes abroad, who may have been exposed to different processes of suspected $\mathrm{ADR}$ reporting and experiences with pharmacovigilance activities in general [8]. The objective of the present study was to describe pharmacists' knowledge, experiences, attitudes and perceived barriers to ADR reporting in Qatar.

\section{Methods}

\section{Sample}

Using workplace contact information, all known pharmacists in Qatar $(n=$ 568) were invited by email to participate in an anonymous web-based survey. The research was approved by both the University of Qatar and London School of Hygiene and Tropical Medicine institutional review boards.

\section{Questionnaire development}

A comprehensive review of the English language literature was conducted using pertinent electronic health databases (PubMed, Embase, International Pharmaceutical Abstracts, Cumulative Index to Nursing and Allied Health Literature) from 1990 to December 2010 using a combination of predetermined keywords and phrases. Hand-searching of references of retrieved articles was also performed. The questionnaire was developed according to the domains of interest evaluated in this existing literature: subject demographics; ability to detect suspected ADRs (knowledge); experiences reporting suspected ADRs; attitudes towards the pharmacists' role in ADR reporting; perceived barriers and facilitators to suspected ADR reporting; and recommendations for improvements in this process locally. The questionnaire draft was formatted as an electronic survey and reviewed for face and content validity and piloted by a small randomly selected group of Qatari pharmacists.

\section{Analysis}

Incomplete surveys were analysed if a response to the dependent variable question (history of suspected ADR reporting in Qatar) was given. Frequencies of correct answers to ADR knowledge questions were assessed. Responses were further stratified according to categorical demographic parameters as well as comparisons between ADR reporters and non-reporters. Univariate and multiple logistic regression analyses were used to examine differences in ADR reporting (dependent variable) among pharmacists according to a priori defined criteria including independent variables: age; sex; years in practice; and practice setting. All data analyses were conducted using SPSS for Mac $\mathrm{Ma}^{\circ}$, version 19.0 .

\section{Results}

\section{Background characteristics}

The survey remained open between 30 April and 30 June 201 1. Of the 142/568 responses (25.0\% response rate), 116 (81.7\%) surveys included information about prior experiences with reporting suspected ADRs.

A total of 17 different countries of origin were represented and almost half of pharmacists had practised in Qatar for $<5$ years (Table 1 ). Most respondents represented hospital inpatient practices (64.0\%). Only 14 (12.1\%) had never worked in a hospital pharmacy.

\section{Knowledge of ADRs}

Pharmacists' knowledge of ADR terminology was assessed and over $90 \%$ identified the World Health Organization description of an ADR; however, approximately 1 in 5 selected statements were inconsistent with accepted ADR descriptions. Most pharmacists were able to correctly distinguish an ADR from a medication error $[9,10]$.

\section{Experience of ADR reporting}

Less than half of the respondents (49, 42.2\%) had made suspected ADR reports in the past and 34 (29.3\%) reported doing so in Qatar. Most of these local reports $(29,85.3 \%)$ were by hospital pharmacists, 4 (11.7\%) from ambulatory clinics and 1 from a nondirect patient care position. None of the community pharmacists surveyed had ever made a suspected ADR report in Qatar. Reporters mostly submitted 


\begin{tabular}{|c|c|c|}
\hline Variable & \multicolumn{2}{|c|}{ Value } \\
\hline \multirow{3}{*}{ Age (years) } & \multicolumn{2}{|c|}{ Mean (SD) } \\
\hline & \multicolumn{2}{|c|}{$36.2(8.3)$} \\
\hline & No. & $\%$ \\
\hline Sex (female) & 61 & 52.6 \\
\hline \multicolumn{3}{|l|}{ Country of origin $(n=114)^{a}$} \\
\hline Qatar & 4 & 3.4 \\
\hline Other GCC country & 1 & 0.9 \\
\hline Egypt & 40 & 34.5 \\
\hline Jordan & 13 & 11.2 \\
\hline Other Middle Eastern country & 13 & 11.2 \\
\hline Sudan & 21 & 18.1 \\
\hline Other African country & 3 & 2.6 \\
\hline India/Pakistan & 8 & 6.9 \\
\hline Philippines & 5 & 4.3 \\
\hline Canada/United States & 5 & 4.3 \\
\hline United Kingdom & 1 & 0.9 \\
\hline \multicolumn{3}{|l|}{ Highest pharmacy degree } \\
\hline Bachelors & 102 & 87.9 \\
\hline Masters & 9 & 7.8 \\
\hline Doctorate (PhD or PharmD) & 5 & 4.3 \\
\hline \multicolumn{3}{|l|}{ Year of highest pharmacy degree } \\
\hline $2000-11$ & 62 & 53.4 \\
\hline 1990-99 & 38 & 32.8 \\
\hline 1980-89 & 12 & 10.3 \\
\hline $1970-79$ & 4 & 3.4 \\
\hline \multicolumn{3}{|c|}{$\begin{array}{l}\text { Country where highest pharmacy degree obtained } \\
(n=109)\end{array}$} \\
\hline GCC country & 2 & 1.7 \\
\hline Egypt & 41 & 35.3 \\
\hline Jordan & 20 & 17.2 \\
\hline Other Middle Eastern country & 7 & 6.0 \\
\hline Sudan & 12 & 10.3 \\
\hline Other African country & 2 & 1.7 \\
\hline India/Pakistan & 10 & 8.6 \\
\hline Philippines & 5 & 4.3 \\
\hline Other European or Asian country & 2 & 1.7 \\
\hline United Kingdom & 6 & 5.2 \\
\hline Canada/United States & 2 & 1.7 \\
\hline \multicolumn{3}{|c|}{ Duration of working as a pharmacist (years) $(n=115)$} \\
\hline$<2$ & 6 & 5.2 \\
\hline $2-5$ & 14 & 12.1 \\
\hline $6-10$ & 41 & 35.3 \\
\hline 11-15 & 26 & 22.4 \\
\hline$<15$ & 28 & 24.1 \\
\hline
\end{tabular}

their documentation to their hospitals (97.0\%), but also directly to the SCH (14.7\%) or drug manufacturer (5.9\%); 18 (52.9\%) described receiving some form of acknowledgement for their submission. When asked to describe the ultimate fate of a submitted suspected ADR report in Qatar, over half of all surveyed pharmacists (54.3\%) were unsure.

\section{Attitudes and barriers to ADR reporting}

Respondents uniformly agreed with the aims of pharmacovigilance activity to promote new understanding of medication; patient safety; and transparency of reporting. A high proportion (84.4\%) felt that suspected ADR reporting was a professional obligation and if faced with a patient experiencing a serious ADR, the majority (90.5\%) thought they would initiate a suspected ADR report.

Although many respondents agreed that lack of access to a reporting form and remuneration were problematic, a larger proportion disagreed that these issues were barriers. Time constraints were also rated low $(21.2 \%)$ as a potential impediment. Inability to recognize a suspected ADR was a barrier stated by $39.4 \%$ of respondents. Pharmacists identified an increased likelihood of reporting a suspected ADR if the reactions were: serious for the patient (96.2\%); novel (90.2\%) or associated with a new medication (88.8\%); and if some acknowledgment was offered (75.2\%). Many respondents (81.6\%) felt more pharmacovigilance training and an ability to submit online (68.6\%) would facilitate reporting.

\section{Factors influencing ADR reporting}

There were no significant differences among respondents when stratified according to sex, age, practice setting 


\begin{tabular}{|c|c|c|}
\hline \multicolumn{3}{|c|}{$\begin{array}{l}\text { Table } 1 \text { Demographic characteristics of pharmacists responding to the survey of } \\
\text { adverse drug reporting }(n=116) \text { (concluded) }\end{array}$} \\
\hline Variable & \multicolumn{2}{|c|}{ Value } \\
\hline Duration of practice in Qatar (years) $(n=109)$ & No. & $\%$ \\
\hline$<2$ & 21 & 18.1 \\
\hline $2-5$ & 27 & 23.3 \\
\hline $6-10$ & 42 & 36.2 \\
\hline $11-15$ & 14 & 12.1 \\
\hline$<15$ & 12 & 10.3 \\
\hline \multicolumn{3}{|l|}{ Pharmacy practice site } \\
\hline Community & 19 & 16.4 \\
\hline Ambulatory care (private or public) $(n=5)$ & 16 & 13.8 \\
\hline Hospital (private or public) $(n=3)$ & 72 & 64.0 \\
\hline Other & 9 & 7.8 \\
\hline
\end{tabular}

${ }^{a}$ Examples of countries represented in the categories include: GCC (Oman, Kuwait); other Middle Eastern (Lebanon, Palestine, Syrian Arab Republic); other African (Nigeria, South Africa). $G C C=$ Gulf Cooperation Council; $S D=$ standard deviation .

and years in practice (Table 2). Only availability of an ADR form was considered a greater barrier for ambulatory care pharmacists when compared with their hospital-based colleagues ( $11.4 \%$ versus $40.3 \%, P=0.002$ ). When controlling for all other factors in the model, respondents working in hospital settings were over 7 times more likely to have reported a suspected ADR in Qatar. greater than that reported elsewhere recently $[2,5]$. Respondents illustrated a good understanding of purpose and positive attitudes towards suspected $\mathrm{ADR}$ reporting by pharmacists as the majority considered it a professional obligation.

One-third of respondents had submitted a suspected ADR report in Qatar. This rate is higher than in community pharmacist populations documented recently in the region (approximately $10 \%$ in Saudi Arabia, 21\% in Turkey), but within reported ranges when surveys among hospital pharmacists in the past decade are considered $[2,6]$. Hospital pharmacists were most likely to have made a suspected ADR report and this is consistent with studies conducted elsewhere. Factors for such inpatient site-related differences in reporting have been previously proposed and include greater familiarity with pharmacovigilance; constant contact with patients experiencing serious ADRs; and close relationships with physicians who may delegate reporting of ADRs. When controlling for other variables in our model, increased age was also

\begin{tabular}{|c|c|c|c|c|c|c|}
\hline \multirow[t]{2}{*}{ Characteristic } & \multicolumn{2}{|c|}{$\begin{array}{l}\text { Ever reported ADR } \\
\text { in Qatar }\end{array}$} & \multicolumn{2}{|c|}{ Crude analysis } & \multicolumn{2}{|c|}{ Adjusted analysis ${ }^{a}$} \\
\hline & No & Yes & OR $(95 \% \mathrm{Cl})$ & $P$-value & OR $(95 \% \mathrm{Cl})$ & $P$-value \\
\hline \multicolumn{7}{|l|}{ Sex } \\
\hline Male & 34 & 20 & 1.00 & & & \\
\hline Female & 47 & 14 & $0.51(0.23-1.14)$ & 0.100 & $0.33(0.11-0.95)$ & 0.04 \\
\hline Age $(\text { years })^{b}$ & & & $1.01(0.96-1.06)$ & 0.653 & $0.86(0.76-0.99)$ & 0.03 \\
\hline \multicolumn{7}{|l|}{ Practice site } \\
\hline Outpatient & 31 & 4 & 1.00 & & & \\
\hline Inpatient & 43 & 29 & $5.23(1.67-16.4)$ & 0.002 & $7.42(1.90-27.8)$ & 0.003 \\
\hline \multicolumn{7}{|c|}{ Duration of practice in Qatar (years) } \\
\hline$<2$ & 19 & 2 & 1.00 & & & \\
\hline $2-5$ & 22 & 5 & $2.15(0.38-12.4)$ & 0.390 & $1.43(0.22-9.40)$ & 0.790 \\
\hline $6-10$ & 11 & 3 & $6.46(1.20-21.4)$ & 0.020 & $11.2(1.60-77.6)$ & 0.020 \\
\hline $11-14$ & 25 & 17 & $2.59(0.37-17.9)$ & 0.340 & $6.78(0.61-75.7)$ & 0.12 \\
\hline$>15$ & 5 & 7 & $13.3(3.50-84.9)$ & 0.006 & 23.7 (6.70-83.8) & 0.003 \\
\hline
\end{tabular}

aAjusted for the effects of the other variables in the table; ${ }^{b}$ In the adjusted analysis, OR of 0.86 indicates that for each additional year of age, a respondent was 0.86 times less likely to reported a suspected ADR in Qatar, controlling for other factors in the model. $O R=$ odds ratio; $C I=$ confidence interval. 
associated with decreased reporting. Older pharmacists in Qatar may have graduated from product-centred education models historically offered in the Middle East region as opposed to more contemporary patient-oriented programmes and, despite greater practical experience, have less clinical confidence in detecting potential ADRs [8]. However, pharmacists with longer practice history in the country in theory have had greater opportunities to encounter, detect and report suspected ADRs in Qatar.

Unavailability of a reporting form has been a stated constraint to voluntary participation in pharmacovigilance activities in other studies [11-13], but this was not a collective barrier in our population; this may be due to the large number of hospital practitioners responding who may have a standard form in place at their site. Pharmacists preferred a single and accessible suspected ADR reporting form with webbased submission capability. Qatar pharmacists did express sentiments similar to both community and hospital pharmacists elsewhere who were unsure if a patient reaction was truly an ADR [14]. Communication and education from regulatory and health professional bodies should emphasize that clinical certainty is not a prerequisite for report submission, as causality assessment can be performed by the pharmacovigilance authority according to documentation of the suspected ADR provided by the reporter.
Uncertainty exists about how submitted suspected ADR reports are handled in Qatar. There is no directive in which reports are automatically advanced to the $\mathrm{SCH}$ from patient care sites and there is no indication that reports received by the $\mathrm{SCH}$ are consistently or systematically addressed. Local (hospitals, primary-care centres) and national (SCH) bodies alike could enhance pharmacovigilance awareness and reporting with implementation of a feedback mechanism; only half of our respondents described receiving some form of acknowledgement for their submission [15].

There were a number of limitations to our survey warranting discussion. Survey completion was by an internet-based questionnaire. Community pharmacies in Qatar do not generally have computers and so pharmacists with limited or no internet access at home may have been disadvantaged. Non-response error compromises the accuracy of our conclusions and may further contribute to selection bias and restrict the generalizability of our study findings. Those who did not participate in the study may have had less pharmacovigilance awareness; therefore our findings regarding knowledge and attitude may be overestimations and the barriers to reporting underestimations. Finally, because it is not possible to access the identity of pharmacists who have made suspected ADR submissions in Qatar, a case-control study methodology to assess the factors associated with ADR reporting was not possible. As our study relies on self-reporting, we cannot confirm pharmacists' declared pharmacovigilance activities.

\section{Conclusions}

The results indicated that pharmacists' workplaces exerted a strong influence on the reporting of suspected ADRs in Qatar. Most responding pharmacists had never submitted a report in the country, although they expressed positive attitudes towards pharmacovigilance activity and good knowledge of its purpose.

\section{Acknowledgements}

The statements made herein are solely the responsibility of the author. The author wishes to thank undergraduate University of Qatar College of Pharmacy students, Hala Sonallah and Amna Fadul, for their efforts in the initial development and translation of the pharmacist survey.

Funding: This report forms one part of a larger project evaluating pharmacovigilance in the Middle East made possible by an undergraduate research experience project award from the Qatar National Research Fund (a member of the Qatar Foundation).

Competing interests: None declared.

\section{References}

1. Belton KJ; The European Pharmacovigilance Research Group. Attitude survey of adverse drug-reaction reporting by health care professionals across the European Union. European Journal of Clinical Pharmacology, 1997, 52:423-427.

2. Toklu HZ, Uysal MK. The knowledge and attitude of the Turkish community pharmacists toward pharmacovigilance in the Kadikoy district of Istanbul. Pharmacy World and Science, 2008, 30:556-562.

3. Bawazir SA. Attitude of community pharmacists in Saudi Arabia towards adverse drug reaction reporting. Saudi Pharmaceutical Journal, 2006, 14:75-83.
4. Al-Sultan MS, Bawazir SA. Adverse drug reaction reporting by hospital pharmacists in Saudi Arabia. Saudi Pharmaceutical Journal, 2009, 17:95-105.

5. Su C, Ji H, Su Y. Hospital pharmacists' knowledge and opinions regarding adverse drug reaction reporting in Northern China. Pharmacoepidemiology and Drug Safety, 2010, 19:217-222.

6. Nita Y, Batty KT, Plumridge RJ. Adverse drug reaction reporting: attitudes of Australian hospital pharmacists and doctors. Journal of Pharmacy Practice and Research, 2005, 35:9-14.

7. Wilbur K. Pharmacovigilance in Qatar hospitals. Pharmaceutical Medicine, 2012, 26:23-25. 
8. Kheir $\mathrm{N}$ et al. Pharmacy education and practice in 13 Middle Eastern countries. American Journal of Pharmaceutical Education, 2009, 72:1-13.

9. World Health Organization. International drug monitoringthe role of the hospital. A WHO report. Drug Intelligence and Clinical Pharmacy, 1970, 4:101-111.

10. Aronson JK. Medication errors: definitions and classification. British Journal of Clinical Pharmacology, 2009, 67:599-604.

11. Irujo $\mathrm{M}$ et al. Factors that influence under-reporting of suspected adverse drug reactions among community pharmacists in a Spanish region. Drug Safety, 2007, 30:1073-1082.

12. Elkalmi RM et al. A qualitative study exploring barriers and facilitators of reporting adverse drug reactions (ADRs) among community pharmacists in Malaysia. Journal of Pharmaceutical Health Services Research, 2011, 2:71-78.

13. Al-Sultan MS, Bawazir SA. Adverse drug reaction reporting by hospital pharmacists in Saudi Arabia. Saudi Pharmaceutical Journal, 2009, 17:95-105.

14. Nebeker JR, Barach P, Samore MH. Clarifying adverse drug events: a clinician's guide to terminology, documentation, and reporting. Annals of Internal Medicine, 2004, 140:795-801.

15. Vallano A et al. Obstacles and solutions for spontaneous reporting of adverse drug reactions in the hospital. British Journal of Clinical Pharmacology, 2005, 60:653-658. 